\title{
ELECTROPHORETIC STUDIES OF GENETIC VARIATION IN NATURAL POPULATIONS OF ALLOGAMOUS LIMNANTHES ALBA AND AUTOGAMOUS LIMNANTHES FLOCCOSA (LIMNANTHACEAE)
}

\author{
MARY T. KALIN DE ARROYO \\ Departamento de Botánica, Escuela de Biología, Universidad Central de Venezuela, \\ Caracas 10098, Venezuela
}

Received 17.vii.74

\section{SUMMARY}

The theoretical prediction that autogamy leads to a reduction in genetic variability is examined by comparing electrophoretic variation for two enzyme systems (peroxidase I and acid phosphatase), tentatively considered to be coded by seven polymorphic and five monomorphic loci, in eight populations each of the highly outcrossed Limnanthes alba, and the variably autogamous species $L$. floccosa.

Although Limnanthes floccosa on the average is slightly less genetically variable than $L$. alba, there is no consistent relationship between the level of genetic variability and the degree of autogamy among populations of $L$. floccosa itself.

\section{INTRODUCTION}

From recent detailed studies of genetic variation in a number of autogamous species (e.g. Kannenberg and Allard, 1967; Harding et al., 1974) there is every indication that autogamous populations may exhibit levels of genetic variability far in excess of that predicted from the level of self-pollination, and that contrary to the usual assumption, no consistent relationship exists between the breeding system and the level of genetic variability. Many autogamous species studied to date share two characteristics: their outcrossing ancestors are wind-pollinated, and their seed is widely dispersed. In this paper the genetic effect of autogamy on population variability is studied in the bee-pollinated genus Limnanthes $\mathrm{R}$. Br. Measurements of genetic variability are compared for $L$. floccosa Howell, which is adapted for autogamy and for $L$. alba Benth., adapted for outcrossing, and considered the immediate ancestor of L. floccosa (Kalin, 1971).

\section{Materials}

Limnanthes species are annuals whose life-cycles are closely governed by the availability of moisture during the spring in their native habitats in California and southern Oregon. L. alba, comprising two varieties (var. alba and var. versicolor), occurs from Merced Co. north to Shasta Co. in California (fig. 1), principally in vernal pools and in other wet habitats. L. floccosa, which comprises five subspecies (Arroyo, 1973a), occurs on the north-eastern edge of the distribution of $L$. alba, extending from Tehama Co., California, north into Jackson Co., Oregon, with one outlying station in Lake Co., California (fig. 1). L. floccosa is highly variable ecologically. 


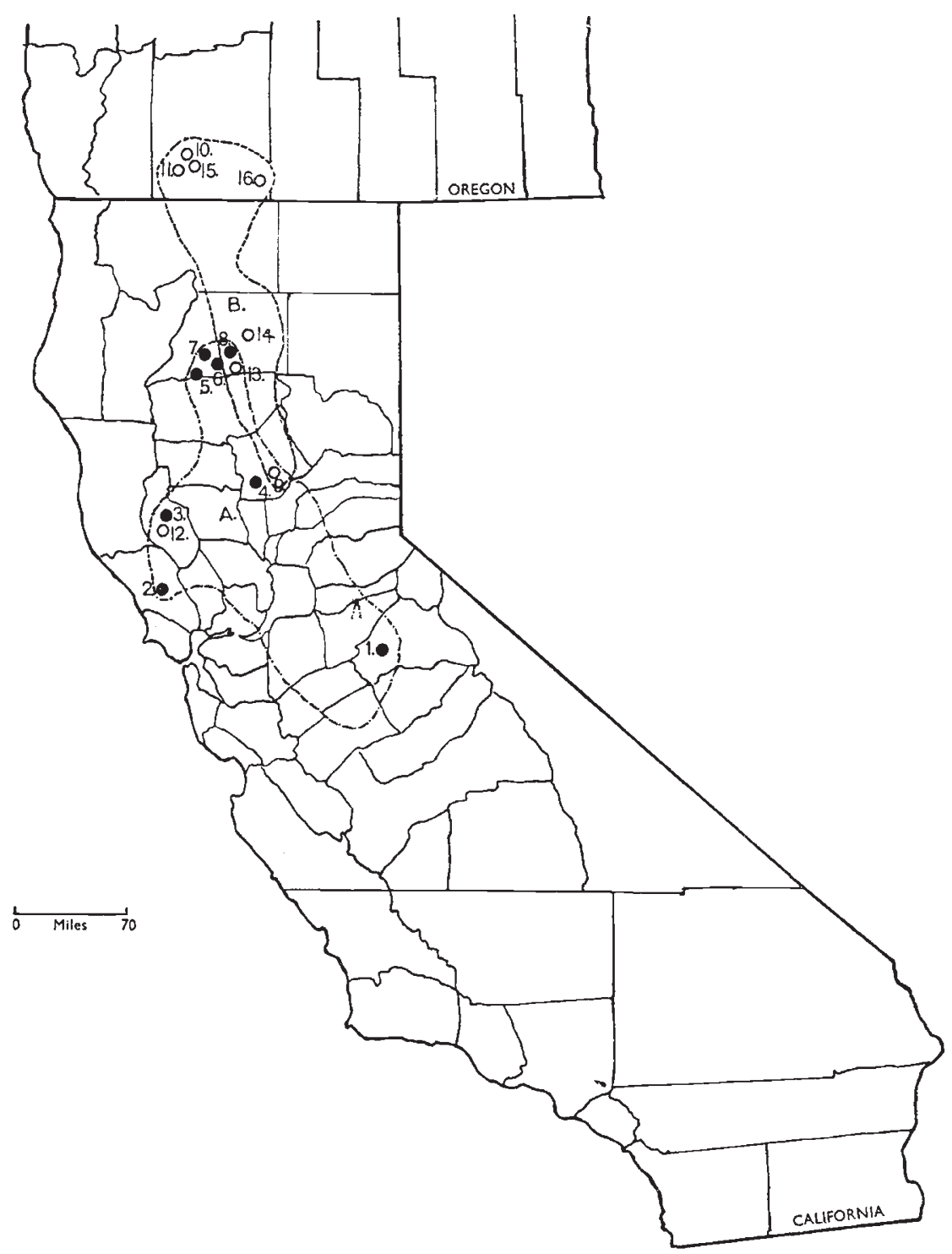

FIG. 1.-Distributions of Limnanthes alba (A) and Limnanthes floccosa (B) in California and southern Oregon, showing in each case the locations of the eight populations studied (closed circles, 1-8: L. alba; open circles, 9-16: L. floccosa). Compare table 1.

Three of its subspecies (ssp. californica, ssp. pumila and ssp. grandiflora) inhabit vernal pools. Subspecies floccosa, in contrast, is a locally common and widespread plant of stony flats, old fields and road edges. Subspecies bellingeriana, which occurs on the extreme eastern edge of the distribution of $L$. floccosa, is found only in shaded, damp meadows, which generally are snow covered for several months of the winter. 
Eight populations were selected from each of the two species (table l). The populations were chosen so as to include both central and marginal areas of the distributions of the species, as well as to cover the range in levels of self-pollination known in the two species (table 3).

TABLE 1

Habitats and numbers of plants assayed for populations of Limnanthes alba and L. floccosa.*

Number of Species and population plants assayed

L. alba var. alba
1. Groveland-1
30
2. Sobre Vista-1
3. Lake Co.-2
4. Shippe-2
5. Palo Cedro-1
35
45
25
40

\author{
Damp meadow in pine woods \\ Grassy field \\ Vernal pool in open field \\ Vernal pool in open field
}

L. alba var. versicolor
6. Bella Vista-1
7. Bella Vista-2
8. Ingot-4
Streamside
Damp meadow
Streamside

L. floccosa ssp. californica
9. Oroville-1
Vernal pool in open field

L. floccosa ssp. grandiflora

10. Camp White-1

L. floccosa ssp. pumila

11. Lower Table Rock-1

L. floccosa ssp. floccosa
12. Lake Co.-1
13. Bear Creek-1
14. Ingot-1
15. Antioch-1

\section{L. foccosa ssp. bellingeriana} 16. Mountain View-1
Vernal pool, open field

Vernal pool, open flat

\section{Habitat}

\author{
Dried lake bed \\ Dry, stony flat \\ Dry flat \\ Roadside, open field
}

Damp, stony flat in pine forest

* Numbers refer to localities in fig. 1.

\section{Methods}

\section{(i) Measurement of self-pollination}

Self-pollination was measured in plants grown in greenhouses from seed collected at each population site. Two measures of self-pollination are provided: automatic selfing ability as directly obtained in the greenhouse, and an estimate of the actual amount of selfing expected in nature, which takes into account the effect at different levels of protandry in the 16 populations. Automatic selfing ability was determined by obtaining the average number of seed set per flower in 15-30 plants screened from pollinators. The expected actual amount of selfing was obtained as the product of the automatic selfing ability and the percentage of flowers in the population ordinarily not prevented from undergoing self-pollination by the prior removal of pollen from the anthers by pollen-collecting bees. 
This last figure was obtained by counting the number of flowers in populations in the field having receptive stigmas, but in which the pollen had not already been removed. Both measures of self-pollination are expressed as a percentage of the seed set obtained in flowers naturally pollinated by bees in the field (this was five nutlets per flower in the $L$. alba populations but only one nutlet per flower in some of the L. floccosa populations).

\section{(ii) Electrophoresis}

The plants employed for electrophoretic analysis were grown from seed collected in the field. The loci examined were peroxidase $I(p e r)$ and acid

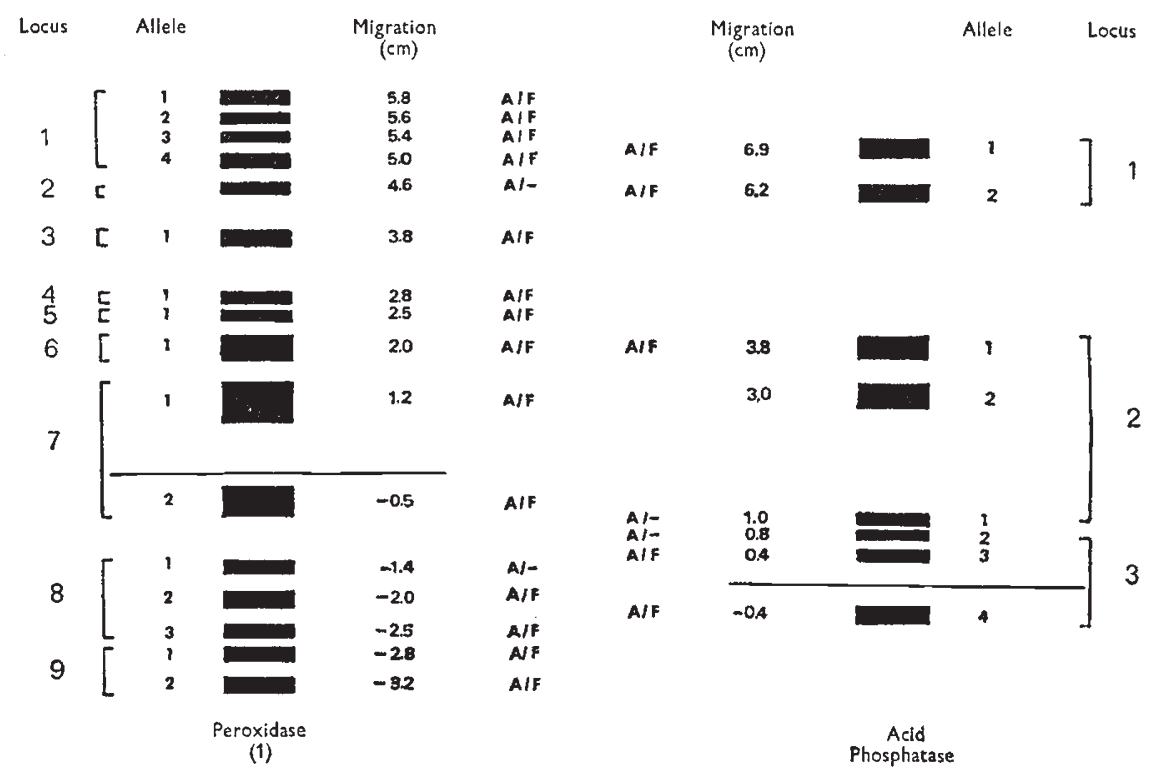

FIG. 2.-Loci, alleles and migration distances of alleles from the origin for the peroxidase and acid phosphatase systems. Peroxidase locus 2, allele no. 1 is referred to as per ${ }_{21}$ in text, etc. A: present in L. alba; F : present in L. floccosa;-absent in L. floccosa.

phosphatase (ap) loci. Peroxidase activity was detected according to Scandalios (1964) and acid phosphatase activity according to Allen et al. (1963). Crude protein extracts were obtained by crushing $1 \mathrm{~cm}$ segments of hypocotyl tissue of 5-15-day-old seedlings, following germination on moist vermiculite at $14^{\circ} \mathrm{C}$ in total darkness.

Electrophoresis was conducted on horizontal starch gels in a discontinuous buffer system $(p \mathrm{H} 8 \cdot 7)$. 10.8 per cent gels were prepared according to Kristjansson (1963) in tris-citrate buffer ( $p \mathrm{H} \mathrm{8.4)}$. The crude protein extracts were absorbed on to $8 \times 9 \mathrm{~mm}$ wicks of Whatman $3 \mathrm{~mm}$ chromatography paper and inserted into slits in the gels. Electrophoresis was conducted at 15-20 ma for 8-10 hours, or until the borate front had migrated $8 \mathrm{~cm}$ from the point of insertion on the samples.

The equivalence of the bands in different populations was established by running combination gels, each accommodating five individuals of three 
separate populations. Bands migrating equal distances are assumed to be genetically identical. Bands which occurred in every individual studied are assumed to represent monomorphic loci (i.e. loci in which both species are represented by single alleles). This conclusion seems reasonable, for if such bands represented alleles of polymorphic loci, all individuals sampled would then be heterozygous, which would be most unlikely. As no formal genetic analysis of the bands has been made, it is here assumed that the five bands occurring consistently in all individuals sampled represent five independently segregating loci. Genetic analysis may reveal, however, that such bands represent fewer than five loci, as would be the case if one allele determined two or more isoenzymes. The procedure followed in defining polymorphic loci is exemplified by the determination of locus $a p_{1}$ (bands $a p_{11}$ at $6.9 \mathrm{~cm}$ from the origin and $a p_{12}$ at $6.2 \mathrm{~cm}$ from the origin; fig. 2). When individuals of a single population are assayed separately, but on the same gel and stained for acid phosphatase, a certain proportion of the individuals exhibit only band $a p_{11}$. In the same gel other individuals éxhibit only band $a p_{12}$. In a large number of the gels, yet another proportion of the individuals exhibit both $a p_{11}$ and $a p_{12}$. The appearance of these fast-moving bands was not associated in any consistent way with any of the other acid phosphatase bands. Thus individuals carrying only one of the two bands, or the two bands simultaneously were found to be associated, for example, with any of three similar combinations of bands $a p_{21}$ and $a p_{22}$. Given the co-varying association of bands $a p_{11}$ and $a p_{12}$, but their independent association with all other phosphatase bands, it is assumed that $a p_{11}$ and $a p_{12}$ represent two alleles of an independently segregating, polymorphic locus, the appearance of bands $a p_{11}$ and $a p_{12}$ singly, representing homozygotes at the locus, while the appearance of the two bands in the same individual representing a heterozygous combination. The determination of other acid phosphatase loci and all polymorphic peroxidase loci was made in a similar manner. Using these conventions, a total of 12 loci (nine peroxidase and three acid phosphatase, of which a total of five are monomorphic and seven polymorphic) have been outlined for $L$. alba and $L$. floccosa. The total number of bands obtained at each locus for the two species and the distribution of the bands in each of the two species is illustrated in fig. 2.

\section{BREEDING SYSTEMS}

The floral mechanisms determining breeding behaviour in Limnanthes alba and $L$. floccosa have been discussed in detail elsewhere (Arroyo, 1973a, $b$ ). Both $L$. alba and L. floccosa are self-compatible. L. alba, however, is strongly adapted for outcrossing, and self-pollination is largely prevented by its protandrous nature. In the greenhouse, automatic self-pollination resulted in a seed set 3.5-32 per cent of that achieved by plants growing under natural conditions. L. floccosa is adapted for autogamy. In greenhouses, populations of this species set 69-100 per cent of the seed set in the field, by automatic self-pollination. The adjusted estimates indicate, however, that the actual levels of selfing occurring in $L$. alba populations $(0 \cdot 25-3 \cdot 5$ per cent) are very low. The range in $L$. floccosa (21-95 per cent) is wide, a number of the populations having more than 90 per cent selfing. 


\section{Elegtrophoretic variation}

A total of nine peroxidase and three acid phosphatase loci were tentatively defined in the gels (fig. 2). Five peroxidase bands exhibited no detectable variation $\left(\right.$ per $_{2}$, per $_{3}$, per $_{4}$, per $_{5}$, per $\left._{6}\right)$ and are considered as monomorphic loci. Two, three or four bands appeared at each polymorphic locus. Individuals carried one or two bands at each polymorphic locus.

The electrophoretic spectra of $L$. alba and $L$. floccosa are exceedingly similar (fig. 2). Apart from four bands which appeared sporadically in $L$. alba $\left(\right.$ per $_{14}$, per $_{81}, a p_{21}, a p_{31}$ ), all other bands appeared in the two species.

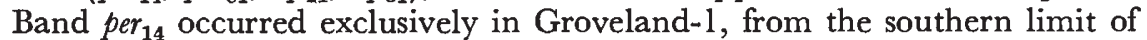
the distribution of $L$. alba, while $a p_{31}$ appeared in both Groveland-1 and Sobre Vista-1. $A p_{21}$ is unique to $L$. alba var. versicolor. This band has also been recorded in another Limnanthes species, L. gracilis, which on the basis of morphological and cytological evidence is believed to be closely related to $L$. alba var. versicolor. $P_{e r}$ occurs in low frequencies in a number of populations of both varieties of $L$. alba. It is, however, notably absent from the north-central area of the species range, where $L$. floccosa is believed to have evolved. The distribution of $a p_{12}$ is noteworthy. It is present in all $L$. alba populations with the exception of Shippe-2. It also appears in the highly autogamous populations Antioch-1 and Mt. View-1 of L. floccosa, but is curiously absent from other populations of this species.

\section{Intrapopulational variability}

The observed percentage of heterozygous individuals per locus and several other estimates of genetic variability are presented for each of the populations studied in tables 2 and 3 . The mean percentage of polymorphic

TABLE 3

Observed proportions of individuals heterozygous per locus in populations of Limnanthes alba and Limnanthes floccosa

\begin{tabular}{|c|c|c|c|c|c|c|c|}
\hline \multirow{2}{*}{$\begin{array}{l}\text { Species and } \\
\text { population }\end{array}$} & \multirow{2}{*}{$\begin{array}{l}\text { Variety or } \\
\text { subspecies }\end{array}$} & \multicolumn{6}{|c|}{ Loci* } \\
\hline & & $a p_{1}$ & $a p_{3}$ & per $_{1}$ & per $_{7}$ & per $_{8}$ & per $_{9}$ \\
\hline \multicolumn{8}{|l|}{ Limnanthes alba } \\
\hline Groveland-1 & alba & $0 \cdot 13$ & $0 \cdot 10$ & 0.60 & $0 \cdot 22$ & $0 \cdot 07$ & 0.66 \\
\hline Sobre Vista-1 & $a l b a$ & 0.85 & - & 0.33 & $0 \cdot 10$ & 0.05 & 0.50 \\
\hline Lake Co.-2 & alba & - & $0 \cdot 12$ & 0.70 & 0.07 & 0.04 & $1 \cdot 00$ \\
\hline Shippe-2 & $a l b a$ & $0 \cdot 16$ & - & 0.46 & $0 \cdot 10$ & - & $0 \cdot 40$ \\
\hline Palo Cedro-1 & $a l b a$ & 0.42 & $0 \cdot 12$ & $1 \cdot 00$ & - & 0.75 & 0.25 \\
\hline Bella Vista-1 & versicolor & $0 \cdot 15$ & $0 \cdot 32$ & 0.40 & - & $0 \cdot 19$ & 0.44 \\
\hline Bella Vista-2 & versicolor & - & $0 \cdot 10$ & $1 \cdot 00$ & - & $0 \cdot 15$ & 0.40 \\
\hline Ingot-4 & versicolor & $0 \cdot 18$ & - & 0.85 & - & $0 \cdot 18$ & 0.26 \\
\hline \multicolumn{8}{|l|}{ Limnanthes floccosa } \\
\hline Oroville-1 & californica & - & $0 \cdot 10$ & $0 \cdot 84$ & - & 0.88 & $1 \cdot 00$ \\
\hline Camp White-1 & grandifiora & - & 0.56 & 0.22 & 0.05 & 0.09 & $0 \cdot 24$ \\
\hline L. Table Rock-1 & pumila & - & $0 \cdot 64$ & 0.05 & $0 \cdot 15$ & 0.30 & $0 \cdot 10$ \\
\hline Lake Co.-1 & floccosa & - & $0 \cdot 64$ & 0.05 & - & - & - \\
\hline Bear Creek-1 & floccosa & - & 0.03 & 0.48 & $0 \cdot 10$ & 0.50 & 0.66 \\
\hline Ingot-1 & floccosa & - & 0.82 & 0.96 & - & 0.55 & 0.03 \\
\hline Antioch-1 & floccosa & $0 \cdot 15$ & 0.66 & 0.40 & - & 0.05 & 0.03 \\
\hline Mt. View-1 & bellingeriana & $0 \cdot 13$ & - & - & - & - & $0 \cdot 11$ \\
\hline
\end{tabular}

* All individuals at loci $a p_{2}$, per $_{2}, \operatorname{per}_{3}, \operatorname{per}_{4}$ and per $_{5}$ were homozygous. 


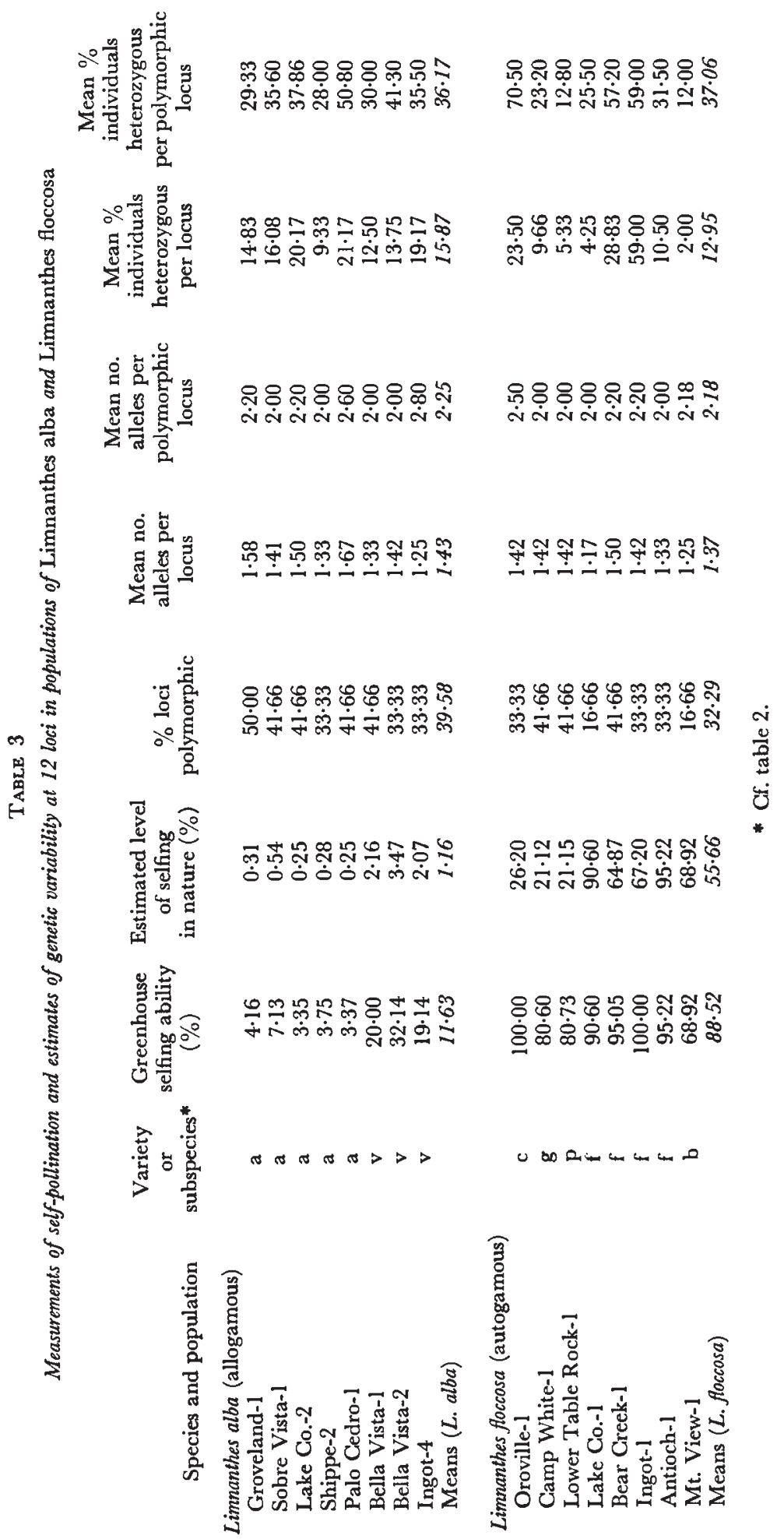


loci per population (i.e. mean percentage of the 12 loci that show two or more alleles) is slightly higher than in the outcrossed $L$. alba (33-50 per cent; mean 39.6 per cent, versus $17-42$; mean $32 \cdot 3$ per cent in $L$. floccosa). There is no indication for an association between increase in the level of autogamy and the number of monomorphic loci in the populations. Populations of $L$. floccosa such as Bear Creek-1, Antioch-1 and Ingot-1, in which the level of autogamy is very high, have numbers of polymorphic loci similar

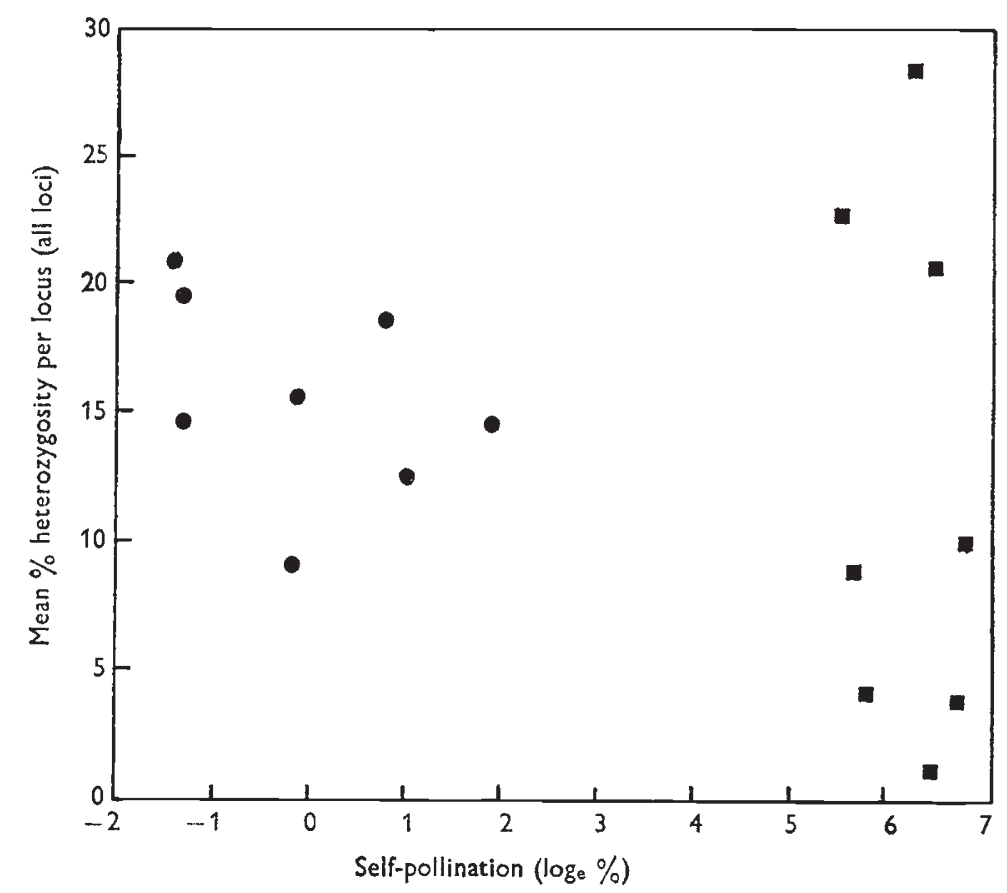

Fig. 3.-Mean percentage of heterozygous individuals per locus, calculated over all loci (polymorphic and monomorphic) plotted against the level of self-pollination (expressed logarithmically). Circles: L. alba; squares: L. floccosa

to those obtained in the highly outcrossed $L$. alba. It is significant, nevertheless, that the two populations of L. floccosa (Mt. View-1 and Lake Co.-1) having very low numbers of polymorphic loci, also have very high levels of autogamy.

The mean percentage of heterozygous individuals per locus per population (estimated on the basis of all loci) is interesting. Although the mean is lower for $L$. floccosa (13.0 compared with 15.9 in $L$. alba), there are populations of $L$. floccosa that have a higher percentage of heterozygous individuals than obtained in any of the $L$. alba populations. Mt. View ( $2 \cdot 0$ per cent) and Lake Co.-1 (4.25 per cent) populations of $L$. floccosa exhibit the lowest percentage of heterozygous individuals. There is, however, no clear-cut relationship between this measure of genetic variability and the level of autogamy when all populations are considered collectively (fig. 3 ).

When heterozygosity is considered on the basis of polymorphic loci alone a similar pattern emerges. The mean percentage of heterozygous individuals per locus per population is exceedingly similar in the two species $(L$. alba: 
mean for all populations $36 \cdot 2 ; L$. floccosa: mean for all populations $36 \cdot 1$ ). The populations of $L$. floccosa (range $12 \cdot 0-70 \cdot 5$ per cent) are a great deal more variable than those of $L$. alba (range 29-51 per cent) in this respect. A high level of autogamy is associated with a depression in the amount of heterozygosity in some populations of L. floccosa (e.g. Mt. View-1 and Lake Co.-1), but is associated with relatively high levels of heterozygosity in others (e.g. as in Bear Creek-1). The relationship between heterozygosity and the level of autogamy is depicted in fig. 4.

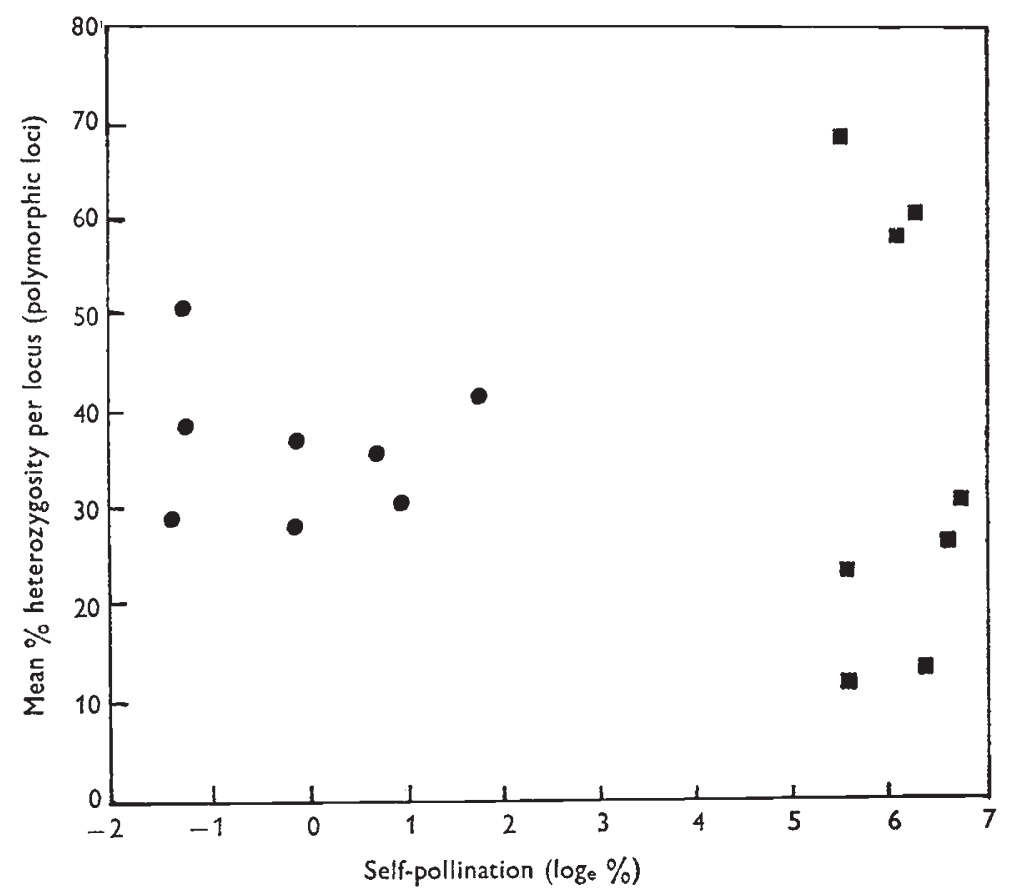

FIG. 4.-Mean percentage of heterozygous individuals per polymorphic loci (circles: $L$. alba; squares: L. floccosa) plotted against the level of self-pollination (expressed logarithmically).

\section{Discussion}

Limnanthes floccosa is believed to have evolved by way of selection for early-maturing, self-pollinating genotypes in marginal populations of $L$. alba (Arroyo, 1973b). No new alleles in the enzyme systems studied have been acquired by $L$. floccosa since its origin.

The mean values of 39.6 per cent polymorphic loci in Limnanthes alba and 32.3 per cent polymorphic loci in $L$. floccosa are of similar order to the 54 per cent and 31 per cent polymorphic loci obtained in the highly selfpollinating Avena fatua and $A$. barbata (Marshall and Allard, 1970) and compare favourably with estimates for the fish genus Astyanax (Avise and Selander, 1972). The values for these organisms fall short of the 63.3 per cent polymorphic loci in the clam Tridacna maxima (Ayala et al., 1973) and the 60 per cent polymorphic loci in the sibling species of the Drosophila 
willistoni group (Ayala et al., 1972a,b), but greatly exceed the average value of 10 per cent polymorphic loci in the predominantly asexually reproducing Lycopodium lucidulum (Levin and Crepit, 1973). It should be borne in mind, however, that if genetic analysis should prove that the five consistently occurring peroxidase bands, here considered as independent loci, actually represent fewer monomorphic loci, the estimates of polymorphic loci per population for all populations of $L$. floccosa and $L$. alba would be somewhat higher.

Although a lower percentage of heterozygous individuals per locus and a lower average percentage of polymorphic loci occurs in the autogamous Limnanthes floccosa as compared with $L$. alba, which is adapted for outcrossing, there is a lack of correspondence between these variables among individual populations of L. floccosa itself. Imam and Allard (1965), Allard (1965), Marshall and Allard (1970), Hamrick and Allard (1972) and Harding et al. (1974) conclude that highly selfing populations may be as genetically variable as outcrossed populations. Rick (1966), however, has shown that autogamous populations of Galápagos Island tomatoes are less morphologically variable than mainland, outcrossing South American populations, while Strid (1969) reaches a similar conclusion in comparing autogamous and closely related allogamous species of Nigella. Recently, moreover, Solbrig (1972) has shown that a number of self-compatible species of Leavenworthia are less genetically variable than other self-incompatible species of the genus. The results obtained here suggest that neither of these extremes adequately characterises autogamous $L$. floccosa, but that its individual populations are highly variable with respect to the amount of genetic variability contained therein.

Considering all measures of genetic variability collectively, it is clear that two distinct levels of variation occur in $L$. floccosa. In populations Bear Creek-1, Oroville-1, Ingot-1 and Antioch-1 the level of variability compares favourably with that in many $L$. alba populations. In populations Mt. View-1, Lake Co.-1, L. Table Rock-1, however, genetic variability falls well below that obtained in the average $L$. alba population. In both groups of populations, however the level of selfing varies between 26 and 95 times that in L. alba.

The apparent explanation for the two levels of variability in $L$. floccosa appears not to be autogamy per se, but autogamy in combination with the degree of population isolation, population size, and mode of population origin. The four populations of the species having relatively high levels of genetic variability all originate from central areas of the species distribution, where $L$. floccosa characteristically forms continuous networks of populations which expand and contract annually with fluctuations in the winter rainfall. Despite the often very high level of autogamy in these populations, they nevertheless exhibit a high percentage of polymorphic loci. The lack of allele fixation is probably due to a combination of origin by fragmentation, rather than by colonisation by a few individuals, and the repeated introduction of new genetic material during the merging of populations during years of abundant rainfall.

The four populations of Limnanthes floccosa exhibiting relatively low levels of genetic variability, in contrast, are either geographically marginal and isolated populations, or members of two subspecies having highly contracted geographical ranges. In Mt. View-1 and Lake Co.-1 the overriding factor 
determining the low degree of genetic variation is allele fixation in all but two of the 12 loci. As both of these populations probably arose through long-range dispersal involving few propagules, the high level of allele fixation conceivably is due to chance fixation in migrant individuals, combined with the probable extreme levels of autogamy such migrants underwent upon establishment of new populations.

An explanation for the low level of heterozygosity in populations Table Rock-1 and Camp White-1 is less evident. As both of these populations belong to subspecies having highly contracted and probably relictual ranges, the low levels of heterozygosity may be the result of selection for high immediate fitness at certain loci necessary for the survival of the two subspecies. Alternatively, the contracted distributions themselves may be the result of overadaptation and failure to meet current environmental conditions outside their highly restricted ranges.

Acknowledgments. - I thank Robert Ornduff, Department of Botany, University of California, who guided this study, which constitutes part of a doctoral thesis submitted in partial fulfilment of the requirements of the Ph.D. degree at that institution. Financial support from predoctoral fellowships and a research grant from the Chancellor's Patent Fund, University of California, Berkeley, and a Grant-in-Aid of Research from the Society of the Sigma Xi are gratefully acknowledged.

\section{References}

ALLARD, R. W. 1965. Genetic systems associated with colonizing ability in predominantly self-pollinated species. In H. G. Baker and G. L. Stebbins (editors), Genetics of Colonizing Species, pp. 49-75. Academic Press, New York.

ALLEN, s. G., MISGH, M. s., AND MIRSKY, A. M. 1963. Variation in electrophoretically separated acid phosphatases of Tetrahymena. J. Histochem. Cytochem., 11, 706-719.

ARROYO, MARY T. KALIN DE. 1973a. A taximetric study of infraspecific variation in autogamous Limnanthes ffoccosa (Limnanthaceae). Brittonia, 25, 177-191.

ARROYO, MARY T. KALIN DE. 1973b. Chiasma frequency evidence on the evolution of autogamy in Limnanthes ffoccosa (Limnanthaceae). Evolution, 27, 679-688.

AVISE, J. C., AND SELANDER, R. K. 1972. Evolutionary genetics of the cave dwelling fishes of the genus Astyanax. Evolution, 26, 1-19.

Ayala, F. J., POWell, J. R., AND TRACEy, M. L. 1972a. Enzyme variability in the Drosophila willistoni group. V. Genic variation in natural populations of Drosophila equinoxalis. Genet. Res., Camb., 20, 19-42.

AYAlA, F. J., POWEll, J. R., TRAGeY, M. L., MOURÃo, AND PÉREZ-SAlAs, s. $1972 b$. Enzyme variability in the Drosophila willistoni group. Genic variation in natural populations of Drosophila willistoni. Genetics, 70, 113-139.

Ayala, F. J., HedGecock, D., zUmWalt, G. s., AND valentine, J. w. 1973. Genetic variation in Tridacna maxima an ecological analog of some unsuccessful evolutionary lineages. Evolution, 27, 177-191.

HAMRICK, J. L., AND ALLARD, R. W. 1972. Microgeographical variation in allozyme frequencies in Avena barbata. Proc. Nat. Acad. Sci., USA, 69, $2100-2104$.

haRDING, J., MANKINEN, B. C., AND Elliot, M. H. 1974. Genetics of Lupinus. VII. Outcrossing, autofertility, and variability in natural populations of the nanus group. Taxon, 23, 729-738.

IMAM, A. G., AND ALlaRD, R. w. 1965. Population studies in predominantly self-pollinated species. VI. Genetic variability between and within natural populations of wild oats from differing habitats in California. Genetics, 51, 49-62.

KALIN, MARY T. 1971. The Evolution of Autogamy in Limnanthes section Inflexae (Limnanthaceae). Ph.D. thesis, University of California, Berkeley, 273 pp.

KANNEnberG, L. W., AND ALlARD, R. w. 1967. Population studies in predominantly selfpollinated species. VIII. Genetic variability in the Festuca microstachys complex. Evolution, $21,227-240$.

KRISTJANSSON, F. K. 1963. Genetic control of two pre-albumins in pigs. Genetics, 48, 1059-1063. 
LEVIN, D. H., AND CREPIT, W. A. 1973. Genetic variation in Lycopodium lucidulum: a phylogenetic relic. Evolution, 27, 622-632.

MARSHALL, D. R., AND ALLARD, R. W. 1970. Isozyme polymorphisms in natural populations of Avena fatua and A. barbata. Heredity, 25, 373-382.

RICK, C. M. 1966. Some plant-animal relationships on the Galápagos Islands. In R. I. Bowan (editor), The Galápagos; Proc. Symp. Galáp. Int. Sci. Proj., pp. 215-244. Univ. Calif. Press, Berkeley and Los Angeles.

SCANDalios, J. G. 1964. Tissue specific isozyme variation in maize. F. Hered., 55, 281-285. SOLBRIG, O. T. 1972. Breeding systems and genetic variation in Leavenworthia. Evolution, $26,155-160$.

STRID, A. 1969. Evolutionary trends in the breeding system of Nigella. Bot. Notiser, 122, 380-397. 